\title{
Roraima: os paradoxos de um grande incêndio ao fim do milênio
}

\author{
AZIZ NACIB AB'SÁBER
}

$\mathrm{A}$

GEOGRAFIA DAS CATÁSTROFES envolve fatos e processos vinculados aos atributos específicos do território de cada país considerado. Na crônica dos acontecimentos catastróficos registram-se atividades vulcânicas, terremotos, maremotos, tornados violentos e avalanches de gelo. No caso do espaço total do território brasileiro não existem tais tipos de processos espasmódicos. Entretanto, têm ocorrido grandes enchentes que afetam a vida e a funcionalidade de metrópoles, capitais regionais ou até pequenos centros que ficaram, parcial ou totalmente, no caminho das águas. Doutra banda, têm ocorrido grandes incêndios em florestas e cerrados, na Amazônia e no Brasil Central, deslanchados por incúria ou descuidos imperdoáveis ou, ainda, por ações deliberadas e criminosas de alguns atores sociais, ao que se acrescentam epidemias e infecções hospitalares, de conseqüências letais. Nos últimos anos foram constatadas, ainda, ventanias localizadas e arrasadoras em localidades do Sul do país e no interior de São Paulo. Em 1963 ocorreu um caso de vento encanado, por entre arranha-céus, ao longo da Avenida Paulista, considerado como um caso de canyon de vento urbano-metropolitano. Nas periferias da cidade em bairros carentes e favelas têm acontecido catastróficos escorregamentos de terra.

Em termos de processos anormais de interferências climáticas e hidrológicas cíclicas, nada se compara, porém, às perturbações criadas por $E l$ Niño, no espaço total da América Tropical, onde o Brasil ocupa o mais largo espaço territorial e aéreo. Tratando-se de uma interferência que somente ocorre de $13 \mathrm{em} 13$ anos, aproximadamente, com maior intensidade e periculosidade regionais, tem havido uma perda de memória sobre as múltiplas interferências climáticas e hidrológicas de $E l$ Niño, no Brasil. De tal maneira que as conseqüências catastróficas não são registradas ou transmitidas aos governantes que se sucedem no poder. E , assim, $E l$ Niño chega inesperadamente, afetando as mesmas regiões de sempre, porém em localidades e meses diversos. Nessas ocasiões radicalizantes, governantes e técnicos - pegos de surpresa - aceitam sugestões esdrúxulas de seus assessores; são pressionados por consultores e empreiteiras para obras caras e inúteis, e só conseguem alívio psicológico quando a própria natureza corrige o ritmo dos processos espasmódicos, fazendo cessar parte de suas conseqüências. Ninguém se preocupa em saber nada sobre as seqüelas posteriores às catástrofes, após os grandes períodos de secas, enchentes dramáticas ou incêndios agigantados. Há 13 anos, técnicos e pro- 
dutores rurais obrigaram os governantes paulistas da época a derrubarem a barragem do Valo Grande, sob a alegação de que assim seriam corrigidas para sempre as enchentes do Baixo Ribeira. Menos de 15 anos depois, em uma nova interferência de El Niño, ocorreram grandes cheias no vale do Ribeira, devido a chuvadas excepcionais, afetando, desta vez, o seu médio vale inferior. Assim pode-se afirmar que de nada adiantou a construção da ponte que substituiu a barragem do Valo Grande de Iguape. Em Roraima, após as grandes queimadas e incêndios que afetaram os campos limpos do Lavrado por mais de cinco meses seguidos, foram somente as grandes chuvas do fim de março que apagaram as queimadas. Tal como prevíamos. E, agora, governantes inoperantes aproveitam para uma tirada demagógica sobre o enorme incêndio, dizendo que "foi bom porque agora os agricultores ( $s i c)$ não precisam fazer as tradicionais queimas para preparo da terra para o cultivo". A demagogia das autoridades certamente não tem limites, entre nós. Seria bom que eles soubessem que nos últimos 40 anos aconteceram secas prolongadas em Roraima nos anos de 1972, 1985 e 1998.

Pensamos que as conseqüências do período de secura prolongada, sobre o mundo das águas na Roraima, ainda não foram tratadas com a seriedade requerida. É indiscutível que a perda de volume d'água do rio Branco - coletor solista de toda a bacia hidrográfica da porção norte de Roraima - é o termômetro principal dos processos que afetaram profundamente a hidrologia regional. $\mathrm{O}$ rio, que possuía de $800 \mathrm{a} 1.000 \mathrm{~m}$ de largura frente às barrancas fluviais de Boa Vista, teve sua largura reduzida para 100-200 m, no máximo (29-3-1998). O curso do rio, que possuía uma coluna d'água de 4 a $5 \mathrm{~m}$, a despeito das variações sazonais e de uma variabilidade climática habitual, passou a uma espessura média de águas, da ordem de 60 centímetros, podendo ser atravessado a vau, em inúmeros pontos. Enormes bancos de areia solta, que normalmente estavam escondidos abaixo das águas, emergiram. Largas praias de estiagem - designadas na Amazônia pelo nome de "tabuleiros de rios" - foram estabelecidas nas margens do antigo leito, ora para a direita, ora para a esquerda, obrigando o rio Branco a freqüentes estrangulamentos e sinuosidades. Mas, o pior aconteceu com os pequenos cursos d'água afluentes que percorrem as colinas arenosas do Lavrado, ladeados pelas aléas de buritizais, matinhas biodiversas e cajueiros nativos. A evaporação forte, relacionada a muito calor $\left(34^{\circ}\right.$ de temperatura média) e a falta de chuvas por alguns meses, foi suficiente para desperenizar a drenagem do Lavrado, colocando o lençol d'água superficial abaixo do leito dos córregos, igarapés ou riozinhos. Apenas as poucas águas dos rios provenientes das serranias florestadas de oeste garantiram a perenidade do agora esquelético rio Branco (março de 1998). Milagrosamente, os buritizais - galerias resistiram em grande parte à passagem do fogo pelos campos limpos do Lavrado, fato que certamente se deve ao suporte ecológico aluvial, ligeiramente hidratado da beira-rio, e à capacidade de adaptação dos buritis aos climas tropicais continentais. Na paisagem desolada, o alinhamento dos buritis e seus acompanhantes biodiversos, a margem de riachos secos - com fluxos temporariamente "cortados" à moda dos rios do sertão nordestino, na época das secas - oferecia a imagem de uma notável resistência biótica. 
$\mathrm{E}$, por ter visto tudo isto, quando nos perguntavam se o Lavrado corria o risco de desertificação, após tantos meses de calor e secura, respondíamos negativamente. Ultrapassados os efeitos críticos de El Niño, certamente os riachos e igarapés voltarão a correr; as lagoinhas recuperarão suas águas, os capins limpos renascerão no Lavrado, e o rio Branco readquirirá seu volume d'água normal, oscilando de nível segundo a variabilidade climática rotineira, comportando ainda ligeiras oscilações sazonais em seu corpo d'água. A segunda pergunta que nos era encaminhada, referia-se a o que fazer para acabar com os

\section{Convergências}

"O fogo chega ali, queima ferozmente os últimos ervanços secos..." - "Até morrer exaurido à margem dum largo rio seco - aceiro natural ou num descampado já comburido pela estiagem..." - "Depois do fogo (...) há cabanas que se incendiam, animais bravios que fogem...” - "É quando os cães famintos, os caracaras, as acauãs e os gaviões de toda espécie se achêgam a procurar animaleiros assados no imenso braseiro". Gustavo Barroso, Terra de Sol. $3^{\text {a }}$ ed., Rio de Janeiro, Livraria São José, 1956. incêndios que se extenuaram por milhares de quilômetros quadrados de Roraima. Levando em conta os titubeios e a impotência dos órgãos governamentais - estaduais e federais - para combater os numerosos caminhos dos incêndios no Lavrado e nas pontas de serras e morros florestados, nossa resposta era peremptória: só a chegada de chuvas fortes seria capaz de apagar os incêndios incontrolados e por termo às labaredas caminhantes que já haviam afetado os campos limpos e agora penetravam pelo rés-dochão das florestas adjacentes - felizmente as chuvas chegaram um dia depois de nosso regresso a São Paulo,em 31.3.98. Mais do que tudo isso, as chuvas fortes deverão eliminar o gigantesco macrodomo de fumaça que atingiu um terço aproximadamente do estado de Roraima, dificultando a aterrissagem e a decolagem de aviões pertencentes a grandes companhias aéreas. Até 30 de março de 1998, prejuízos econômicos para oEstado e para a população. Ruínas de espaços agrários. Prejuízos na temporada agrícola de colonos e assentados pobres. Morte de gado pertencente a pequenos e médios proprietários, despreparados para combater as queimadas. Receios e temores dos grandes proprietários com relação a suas pastagens e infra-estruturas instaladas. O governo de Roraima, pressionado pelos grandes, e perturbado pela amplitude das notícias e averiguações de organismos internacionais; e, ciente do fracasso de sua iniciativa de abrir "buracos” para obter uma água superficial, temporariamente inexistente (devido o rebaixamento do lençol freático), resolveu pedir recursos federais, sob a alegação de combate aos incêndios; quando na realidade precisava pagar dívidas contraídas para a feitura de seus pseudo-micro açudes ou cacimbas. O governo federal revelou incapacidade total para reter os incêndios, preocupado que estava com as estratégias de reeleição e troca de ministros. Órgãos internacionais, aproveitando-se das catástrofes de Roraima na exce- 
lente reunião organizada em março pelos vereadores da Câmara Municipal de Boa Vista para debater a questão dos incêndios de fevereiro, no espaço ecológico e agrário de Roraima, ouviram depoimentos das mais diferentes personalidades regionais. Idéias, informes e críticas foram colocadas perante um seleto grupo de visitantes, cientistas, autoridades e lideranças indígenas. No seu conjunto a reunião parecia mais um seminário de grande universidade do que um simples ato público,

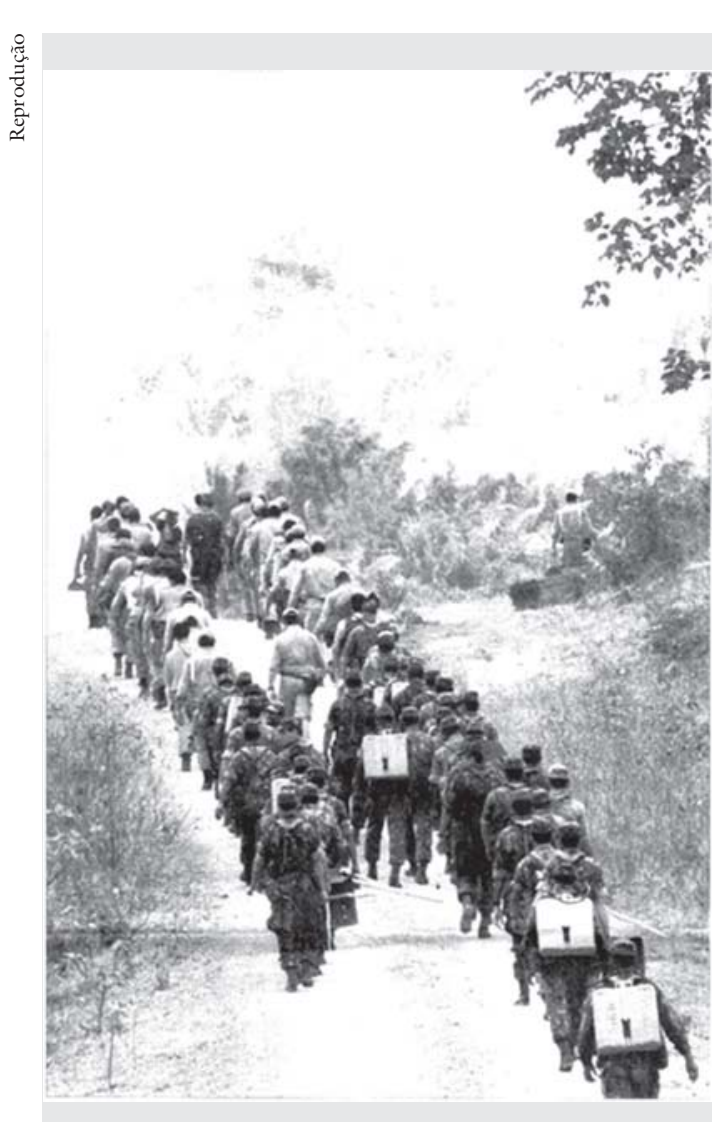
de diferentes atores comunitários. Traduzindo uma preocupação difusa que estava na cabeça de todos, a jovem professora France Rodrigues (UFRR) mostrou sua preocupação com o "quê iria acontecer depois do término dos incêndios". Efetivamente, existem exemplos de que períodos prolongados de secas, seguidos ainda por incêndios derruidores de pequenas propriedades, envolvem graves implicações na estrutura agrária regional. Pequenos proprietários rurais, viventes em áreas de colonização empírica, ou em glebas de assentamentos - desesperados para enfrentar acontecimentos catastróficos, acabam vendendo seus pequenos espaços rurais para vizinhos ou grandes proprietários por preços aviltados. Através de tais ocorrências existem condições para concentração fundiária. E no caso particular de Roraima, uma forte expansão das pastagens, para não falar em eventuais vantagens para a máfia dos garimpos.

Num gesto infame de que "o Brasil demonstra mais uma vez sua incapacidade Tropa anti-incêndio em Roraima de gerenciar a Amazônia", algumas personalidades estrangeiras deixaram estravazar seus secretos desígnos de dominação com relação ao conjunto da Amzônia. Ninguém conseguiu conter os incêndios, os boatos e as desqualificações perversas. Uma situação que se não fosse tão trágica seria no mínimo folclórica. $\mathrm{E}$, doutra banda, o desespero dos pequenos desamparados e dos índios das malocas mais próximas do fogo. Alguns yanomamis, semi-aculturados, procuraram campos de pouso e pequenos aeroportos para fugir. Tranqüilizados, retornaram para a maloca e providenciaram o velho ritual ancestral de chamamento de chuvas. E, enquanto os organismos técnicos previam que só iria chover em fins de abril, as águas chegaram fortes, no último dia de março. Dessa forma, simbolicamente, o fim do século e do milênio na fantástica história da Amazônia, ficou marcado por um episódio para- 
doxal, em que os valores das culturas primárias intentaram corrigir o ritmo da natureza! Enquanto as tecnologias modernas nem bem chegaram a ser ativadas, de modo oportuno, racional e inteligente. Os índios acham que não foi coincidência. Sem comentários. Daqui a 13 anos, quem viver, verá o que acontecerá.

São Paulo, 3 abril de 1998

Aziz Nacib Ab’Sáber, geógrafo, é professor honorário do Instituto de Estudos Avançados da USP e membro do Conselho Editorial da revista ESTUDOS AVANÇADOS. 